\title{
大豆属球蛋白的组分及其与种子 蛋白质总量的关系
}

\author{
林忠 平 \\ （中国科学院植物研究所, 北京) \\ 尹光初雷勃 钧 \\ (黑龙江省农科院大豆研究所, 哈尔滨)
}

\section{引}

大豆以其高蛋白的特点在国计民生中占居重要的地位, 所以对大豆种子蛋白的研究是十 分重要的 ${ }^{[1]}$. 在前文中我们对野生大豆、半野生大豆和栽培大豆的种子蛋白构成做了一个初 步的比较 ${ }^{[2]}$. 本文探索大豆属中种子蛋白积累的总量与蛋白组分之间的关系. 这一工作将有 助于研究大豆高蛋白品种的特点,为选育优质大豆和合理利用大豆原料提供有益的资料.

近年来大豆的育种工作者十分重视开发和利用野生及半野生的大豆资源. 使野生种的高 蛋白和强抗逆性的优良性状向栽培品种转移. 所以本工作的实验材料, 除 13 个栽培品种之外 还包括 5 个野生及 8 个半野生的材料.

\section{材料 和 方 法}

1. 大豆种子黑龙江省的 8 个栽培品种 (Glycine max)、5 个野生系 (Glycine soja) 及 8 个半野生系 (Glycine gracilis) 的种子均收获于黑龙江省农科院试验地. 另外还有 4 个栽培 品种来自陕西省柞水县,一个品种来自陕西富平县.

2. 球蛋白组分的分部采用修改过的 Hill 和 Breidenbach 的方法 ${ }^{[3]}$. 大豆种子去皮后 磨成细粉, 加 10 倍正戊烷 $(\mathrm{V} / \mathrm{W})$ 在室温下脱油三次, 每次 5 小时以上. 脱油的豆粉在空气中 干燥. 0.5 克脱油的豆粉加 $10 \mathrm{ml}$ 蒸馏水,充分研磨, 提取, $13,000 \times \mathrm{g}$ 离心 30 分钟. 取上清液

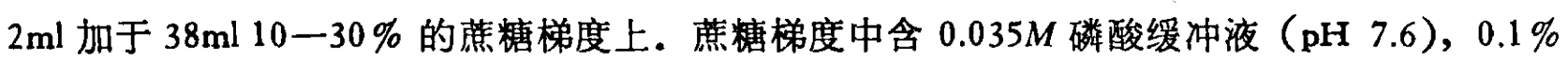
$\beta$-疏基乙醇和 $0.4 \mathrm{M} \mathrm{NaCl}$. 用 Beckman VTi 垂直转头, $140,000 \times \mathrm{g}$ 离心 4 小时. 从离心管 的底部开始, 用蜻动百将溶液送入 HD-81-5 型紫外检测仪. 描记蛋白质的分部情况. 同时 用大豆费蛋白酶抑制剂和牛肝过氧化物酶(前者沉降系数与 $2 \mathrm{~S}$ 球蛋白相当, 后者与 $11 \mathrm{~S}$ 球蛋 白相当)作为标准蛋白在同样的蔗螗梯度上进行超速离心和紫外检测.

3. 蛋白含至的测定去皮种子蛋白含量的测定按 Kjeldahl 法进行. 分部后的蛋白质的 测定依紫外吸收法进行. 蛋白质浓度 $(\mathrm{mg} / \mathrm{ml})=1.45 \times \mathrm{A}_{881}-0.74 \times \mathrm{A}_{2601}$. 试验证实此法测 定的结果与 Lowry-Folin 的方法十分接近.

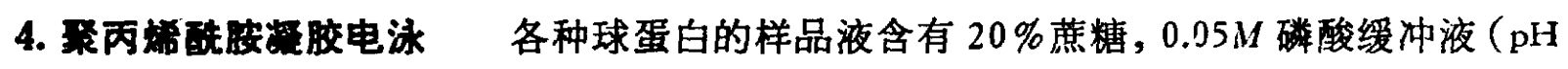

本文 1984 年 7 月 3 日收到。 


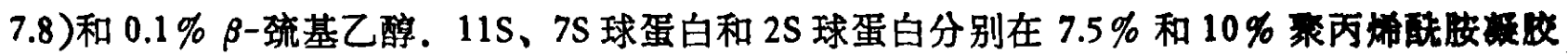
中进行电泳. 电极缓冲液为 $0.05 M$ 磷酸缓冲液 ( $\mathrm{pH} 7-8$ ). 在每柱 $5 \mathrm{~mA}$ 电流下电泳至指示䘞 溴酚蓝移至前沿。胶柱用凝胶电泳扫描。

\section{结 果}

从脱油的豆粉中提出的蛋白质在含有一定离子强度 $(0.4 \mathrm{MNaCl}, 0.035 \mathrm{M}$ 磷酸盐和 $0.13 \mathrm{M}$ $\beta$-统基乙醇）的 10-30\% 蔗糖梯度中分部. 出现三个蛋白质高峰. 根据同标准蛋白的比较 （图 1)及凝胶电泳图谱的鉴定(图 2)，可以判定它们分别是 2S、7S 和11S.

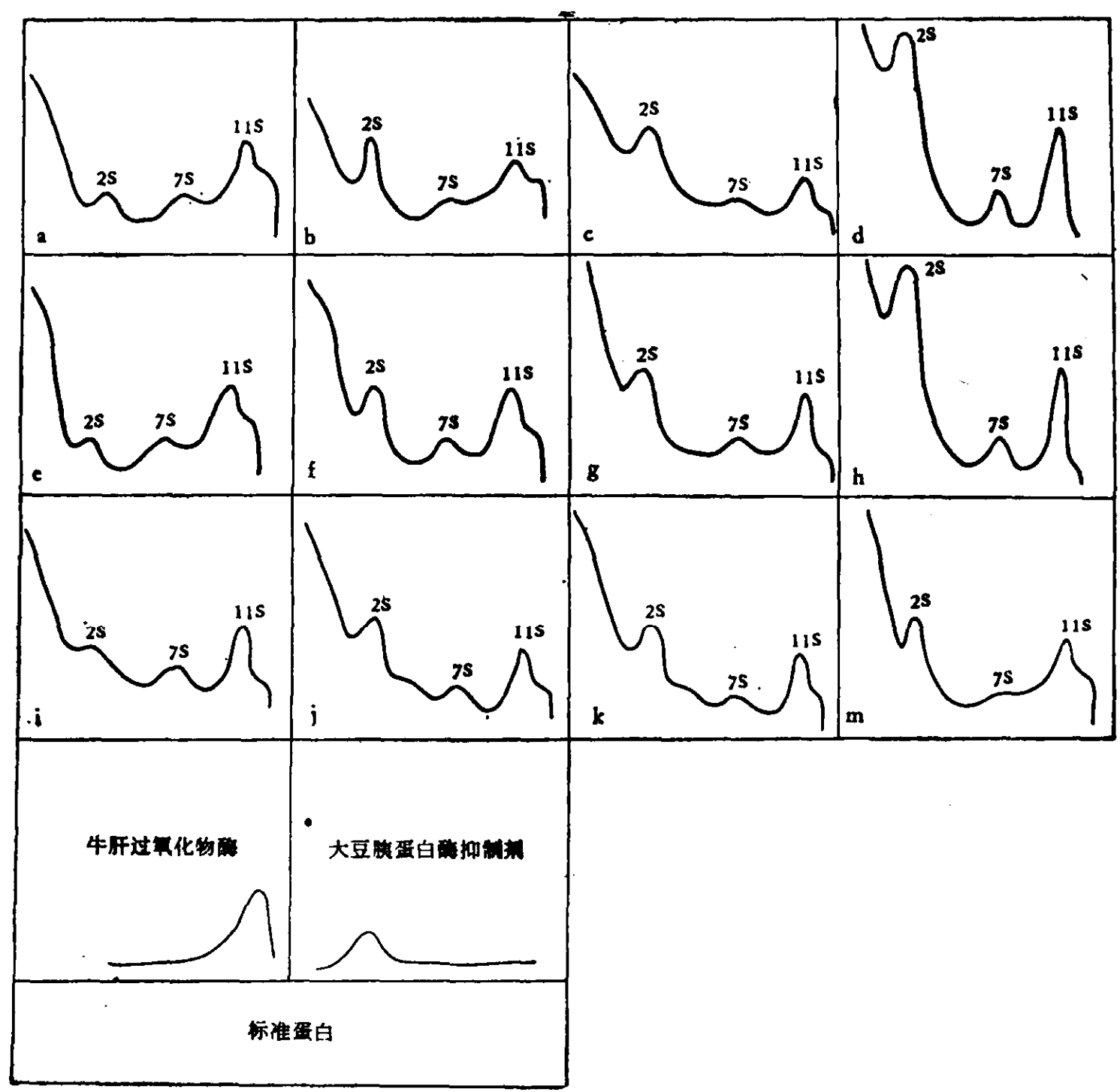

图 1 大豆属球蛋白组分的分部

小图横坐标为离心管从上到下的分部,纵坐标为 $280 \mathrm{~nm}$ 的吸收值

a. 塞凯 20, 总蛋白 $51.67 \%$; b. 国育 41-2, 总蛋白 $51.12 \%$; c. 公 492, 总蛋白 $46.68 \%$; d. 黑河 3 号, 总蛋白 $40.93 \%$ ； c. 龙 79-0616-2, 总蛋白 $60.86 \%$; f. 龙 79-5404, 总叠白 $60.13 \%$; g. 龙 793311 ，总蛋白 $57.22 \%$; h. 龙 $81-5401$, 总蛋白 $53.66 \%$; i. 龙 79-3432-1, 总蛋白 $56.10 \%$; i. 龙 79-4204-5,总蛋白 $54.86 \%$; k. 漠河秝食豆，总蛋白 $46.85 \%$; m. 龙 80-4703, 总蛋白 $46.45 \%$.

a-d 裁培大豆 (G. max); $\mathrm{e}$-h h 野生大豆 (G. soja); i-m 半野生大豆 (G. gracilis)

全部大豆蛋白样品，经超离心分部后都有三种球蛋白的峰，可以看出这些峰的高低及三 
个蜂之间高度上的比例关系，在不同品系的大豆是不一样的. 三种球蛋白会量测定的结果见 于表 1 .

表 1 大豆属种子蛋白组分的测定

\begin{tabular}{|c|c|c|c|c|c|c|}
\hline \multirow{2}{*}{ 种 名 } & \multirow{2}{*}{$\begin{array}{c}\text { 品种名称 } \\
\text { 哉 } \\
\text { 编 }^{\text {号 }}\end{array}$} & \multirow{2}{*}{$\begin{array}{c}\text { 总蛋白含昷 } \\
\text { (\%) }\end{array}$} & \multirow{2}{*}{$\begin{array}{l}\text { 球蛋白在 } \\
\text { 总叠白中 } \\
\text { 的分分比 }\end{array}$} & \multicolumn{3}{|c|}{ 各部分球蛋白的比例(\%) } \\
\hline & & & & $11 \mathrm{~S}$ & $7 \mathrm{~S}$ & $2 s$ \\
\hline \multirow{13}{*}{ G. $\max$} & 塞凯 20 & 51.67 & 75.51 & 55.59 & 28.57 & 15.84 \\
\hline & 北潇 217 & 51.12 & 74.89 & 49.02 & 22.73 & 28.25 \\
\hline & 国育 41-2 & 49.42 & 68.76 & 34.24 & 32.57 & 33.19 \\
\hline & 公 492 & 46.68 & 68.38 & 33.85 & 31.86 & 34.29 \\
\hline & 四粒黄 & 43.96 & 74.18 & 44.61 & 25.65 & 29.74 \\
\hline & 合交 74-1235 & 41.81 & 59.44 & 44.41 & 25.08 & 33.51 \\
\hline & 黑河 3 号 & 40.93 & 53.32 & 24.74 & 32.35 & 42.91 \\
\hline & 合丰 15 & 39.05 & 55.45 & 24.16 & 32.43 & $43 \vdots 41$ \\
\hline & 八月炸* & 50.87 & 53.27 & 50.55 & 21.45 & 28.00 \\
\hline & 色大豆* & 49.37 & 55.68 & 53.08 & 19.86 & 27.06 \\
\hline & 帵豆黄* & 45.38 & 50.39 & 47.74 & 17.06 & 35.20 \\
\hline & 黑色大豆* & 44.73 & 56.73 & 28.96 & 34.36 & 36.68 \\
\hline & 跃进 5 号* & 41.42 & 53.10 & 23.53 & 34.19 & 42.28 \\
\hline \multirow{5}{*}{ G. soja } & 龙 79-0616-2 & 60.86 & 72.48 & 53.25 & 30.65 & 16.10 \\
\hline & 龙 79-5404 & 60.13 & 63.28 & 49.23 & 26.13 & 24.64 \\
\hline & 龙 79-3311 & 57.22 & 60.10 & 34.08 & 34.83 & 31.09 \\
\hline & 龙 81-5401 & 53.66 & 59.65 & 33.40 & 30.58 & 36.02 \\
\hline & 龙 79-0606-1 & 51.71 & 57.43 & 33.13 & 30.67 & 36.20 \\
\hline \multirow{8}{*}{ G. gracilis } & 龙 79-3433-1 & 56.10 & 70.52 & 40.73 & 39.00 & 20.67 \\
\hline & 龙 79-4204-5 & 54.86 & 68.53 & 33.65 & 36.41 & 29.94 \\
\hline & 龙 79-4204-4 & 52.59 & 58.02 & 45.39 & 27.30 & 27.31 \\
\hline & 龙 79-8220 & 49.02 & 65.88 & 41.54 & 22.48 & 35.97 \\
\hline & 龙 79-1802 & 47.20 & 60.62 & 42.01 & 26.65 & 31.34 \\
\hline & 谟河玬食豆 & 46.85 & 77.26 & 40.46 & 29.93 & 29.61 \\
\hline & 龙 80-4703 & 46.45 & 70.28 & 42.38 & 29.27 & 28.35 \\
\hline & 龙 $80-4001$ & 46.33 & $6 . .28$ & 42.61 & 22.41 & 28.98 \\
\hline
\end{tabular}

*来自陕西的种子。

图 1 例举了栽培大豆, 野生大豆及半野生大豆各 4 个品系蛋白质分部情况. 从图 1 和表 1 可以看出: 在野生品系和大多数栽培品种中蛋白质含量高的种子具有较多的 115 球蛋白和 相对少的 $2 S$ 球蛋白,而且高蛋白种子中球蛋白所占的比例也高. 然而在半野生类型的大豆中 未见这种规律性的表现。

\section{讨 论}

在改进谷物和豆类蛋白质质量的育种工作中, 研究种子蛋白质各组分之间的比例关系是 很有意义的. Phodes 和 Jenkins ${ }^{[i]}$ 援引大量资料说明可以通过改变㔻白质的组成来提高禾谷 类籽粒中的赖氨酸和豆类中含硫氨基酸的含量. Millerd 和 Thomson ${ }^{[5]}$ 报道: 在敎豆的各个品 系中 11 蛋白在球蛋白总量中所占的比例变化在 $25 \%$ 到 $80 \%$ 之间. 他们及别的一些作者 ${ }^{[5,6]}$ 
发现 $11 \mathrm{~S}$ 部分比 7S 部分更富于含硫氨基酸. 因而有更高的营养价值. 在大豆中也是如此, 大 豆 $11 \mathrm{~S}$ 部分含硫氨基酸 (尤其是蛋氨酸) 通常比 $7 \mathrm{~S}$ 部分高 3-4 倍. $2 \mathrm{~S}$ 部分也往往含有较多的含硫氨基酸. 在多数 品种中, 尤其是高蛋白的品种, $11 \mathrm{~S}$ 球蛋白的比例很高, 所 以提高 $11 \mathrm{~S}$ 蛋白的含量应是选育优良大豆的一个目 标.

我们将大豆去皮之后进行蛋白的分析，目的是搬开皮 重这个因素. 了解子叶各种蛋白组分的合成与蛋白积累总 量之间的关系。这样做对于具有较厚种皮的野生和半野生 种子尤为必要. 分析的结果表明: 对于许多野生和栽培的 大豆品系来说，11S 蛋白的合成和沉积对于高蛋白性状的 形成是十分重要的.

来自陕西的几个栽培品种球蛋白比例都不高，这可能 与地域或栽培条件的差异有关.柞水县的八月炸、酧豆黄和 色大豆具有较高的 $11 \mathrm{~S}$ 球蛋白和较低的7S球蛋白, 从表 1 可以看出：这三个品种中 $7 \mathrm{~S}$ 球蛋白所占的比例是所有 供试材料中最低的. 我们之所以收集柞水县的这些大豆进 行分析, 是因为群众反映柞水这些豆子出豆腐多, 豆腐好 吃. 看来这些品种在蛋白构成上是有其特点的. 它们也不 同于陕西地区的别的品种，进一步对这些大豆的蛋白组分、 营养价值及食品加工的方面进行研究是很有意义的.

总之,大豆属种子蛋白的构成在不同种,不同品系和不 同地域均存在着差别. 在良种选育中注意其蛋白的组成, 提高 $11 S$ 虽白的组分是十分必要的.

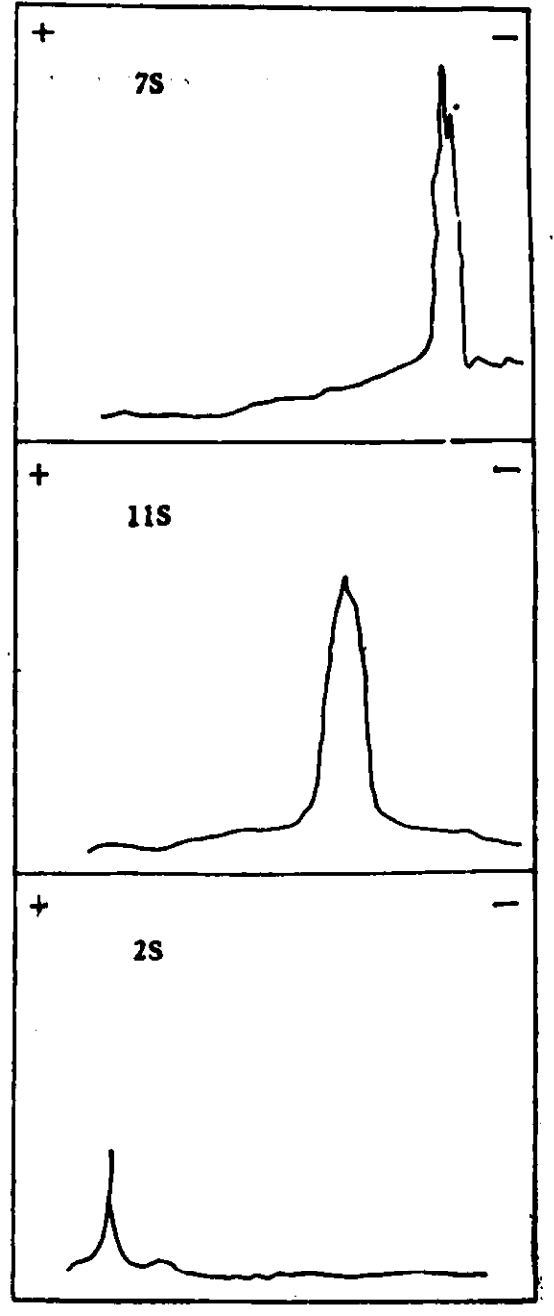

图 2 大豆球蛋白各组分的 稆胶电泳图谱

致谢: 本研究得到王连铮付研究员的指导和帮助, 黑龙江省农科院品种资源室和西安油脂化学研究所 提供试验材料,一并致谢.

\section{\% 文}

[1] 林忠平、尹光初,大豆科学, 1983，2: 232-238.

[2] 雷勃钧、尹光初、刘红军、林忠平,大豆科学, 1984,3: 36-39.

[ 3 ] Hill, J. H. and Breidenbach, R. W., Plant Physiol., 53 (1974), 742-746.

[ 4] Phodes, A. P. and Jenkins, G., in Plant Proteins (Ed. Norton, G.), 1978, 207-226.

[ 5 ] Millerd, A. and Thomson, J., in CSIRO Genetics Report, Division of 'Plant Industry, Canberra, 1975, 58.

[ 6 ] Boulter, D., Evans, I. M. and Derbyshire, E., Qualitas Pl. Mater. Veg., 23(1973), 239. 